Louisiana State University

LSU Digital Commons

4-1-2011

\title{
Tripodfish (Aulopiformes: Bathypterois) locomotion and landing behaviour from video observation at bathypelagic depths in the Campos Basin of Brazil
}

\author{
Matthew P. Davis \\ Louisiana State University \\ Prosanta Chakrabarty \\ Louisiana State University
}

Follow this and additional works at: https://digitalcommons.Isu.edu/biosci_pubs

\begin{abstract}
Recommended Citation
Davis, M., \& Chakrabarty, P. (2011). Tripodfish (Aulopiformes: Bathypterois) locomotion and landing behaviour from video observation at bathypelagic depths in the Campos Basin of Brazil. Marine Biology Research, 7(3), 297-303. https://doi.org/10.1080/17451000.2010.515231
\end{abstract}

This Article is brought to you for free and open access by the Department of Biological Sciences at LSU Digital Commons. It has been accepted for inclusion in Faculty Publications by an authorized administrator of LSU Digital Commons. For more information, please contact ir@lsu.edu. 


\section{Tripodfish (Aulopiformes: Bathypterois) locomotion and landing behaviour from video observation at bathypelagic depths in the Campos Basin of Brazil}

\section{Matthew P. Davis \& Prosanta Chakrabarty}

To cite this article: Matthew P. Davis \& Prosanta Chakrabarty (2011) Tripodfish (Aulopiformes:

Bathypterois) locomotion and landing behaviour from video observation at bathypelagic depths in the Campos Basin of Brazil , Marine Biology Research, 7:3, 297-303, DOI: 10.1080/17451000.2010.515231

To link to this article: https://doi.org/10.1080/17451000.2010.515231

\section{曲 Published online: 18 Mar 2011.}

Submit your article to this journal

山 Article views: 260

Q View related articles 두

4 Citing articles: 1 View citing articles 


\title{
Tripodfish (Aulopiformes: Bathypterois) locomotion and landing behaviour from video observation at bathypelagic depths in the Campos Basin of Brazil
}

\author{
MATTHEW P. DAVIS $\star$ \& PROSANTA CHAKRABARTY \\ Louisiana State University Museum of Natural Science, Baton Rouge, LA, USA
}

\begin{abstract}
A video observation of a deep-sea tripodfish (Aulopiformes: Bathypterois) taken from a remotely-operated vehicle at a depth of $1443 \mathrm{~m}$ in the Campos Basin, Brazil is analysed for swimming and landing movements. The observed specimen is identified here as Bathypterois grallator, and this record is the first video observation of a tripodfish exhibiting periodic swimming followed by landing in a resting position on deep-sea substrate which we interpret as 'bathypteroiform' movement, a locomotive mode unique to taxa within Bathypterois. This observation describes the functional role of the fins associated with landing, including independent movements of the elongated fin ray elements. The specimen is observed to display subcarangiform body and/or caudal fin movement while swimming in a periodic state. Prior to landing, the specimen is observed to raise its elongated caudal fin element parallel to the body, a behaviour that has not been described previously. Following contact of the elongated pelvic fin elements with the deep-sea floor, the elongated caudal fin element is independently lowered, completing the tripod stance typically observed.
\end{abstract}

Key words: Aulopiformes, deep sea, locomotion, tripodfish

\section{Introduction}

Tripodfishes (Family Ipnopidae: Bathypterois) include approximately 19 species of benthic deep-sea fishes that are highly adapted for life along the sea floor (Nelson 2006). Evolutionary adaptations in this group attributed to their deep-sea habit include reduced eyes (Baldwin \& Johnson 1996), simultaneous hermaphroditism, and highly modified pectoral, pelvic, and caudal fin elements (Sulak 1977a). They are distributed worldwide in both temperate and tropical oceans and are commonly found at depths between 250 and $6000 \mathrm{~m}$ (Sulak 1977a). Recent molecular systematic work recovered the genus Bathypterois in the family Ipnopidae within the superfamily Ipnopoidea, a clade comprised of other benthic deep-sea taxa including the telescopefish Gigantura and the deep-sea lizardfish Bathysaurus (Davis 2010).

The pectoral fins of many Bathypterois species have elongated elements that are innervated by enlarged spinal nerves, with a total of three separate spinal nerve innervations supplying the entire pectoral fin in most Bathypterois taxa (Sulak 1977a). As seen in Figure 1, tripodfishes often orientate their pectoral fins in an upright or forward position while they are 'sitting' on the substrate of the sea floor. This has been hypothesized to be a sensory mechanism for detecting the movement of prey (e.g. Sulak 1977a; Carrassón \& Matallanas 2001). The pelvic and caudal fins are also highly modified, with produced elements that allow tripodfishes to sit above the substrate, including pads at the end of each elongated element that protect the rays while in contact with the sea floor. These structures contain no sensory cells and are probably not used for anything other than perching on the seafloor, as the pelvic and caudal fin do not possess the robust nerve innervations of the pectoral fin (Sulak 1977a).

Sulak (1977a) suggested that tripodfishes are filter-feeders that feed on benthopelagic plankton

^Correspondence: Matthew P. Davis, Louisiana State University Museum of Natural Science, 119 Foster Hall, Baton Rouge, LA 70803, USA. E-mail: matthewdavis@1su.edu

Published in collaboration with the University of Bergen and the Institute of Marine Research, Norway, and the Marine Biological Laboratory, University of Copenhagen, Denmark 

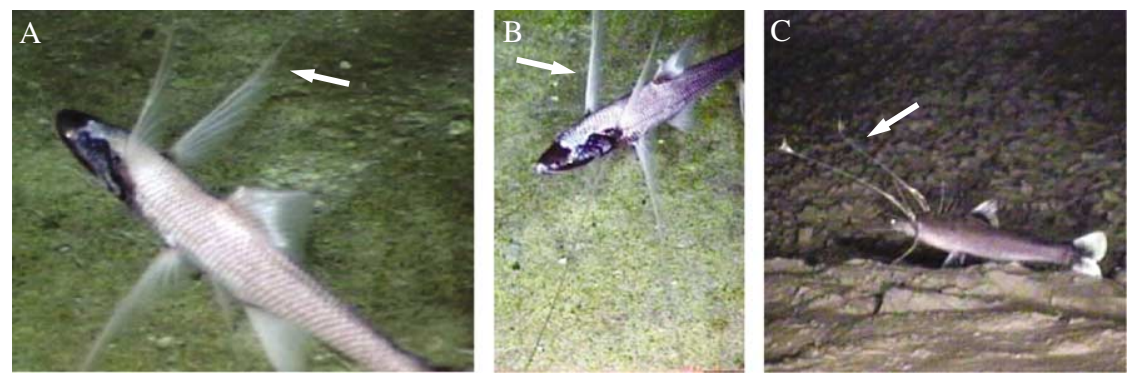

Figure 1. Tripodfishes from the genus Bathypterois resting on deep-sea substrate with pectoral fins upright or in a forward position including (A) B. grallator (Goode \& Bean, 1886), (B) B. grallator and (C) B. bigelowi (Mead, 1958). All images are courtesy of the SERPENT Project (Jones et al. 2010), with identifications by K.J. Sulak and M.P. Davis.

based on the large gape of the upturned (superior) mouth, reduced dentition, and long spinulose gill rakers. Feeding ecology studies of Bathypterois mediterraneus (Bauchot, 1962) identified that the primary food source of adult specimens were benthopelagic plankton, with occasional benthic resources that were mainly suprabenthic (Carrassón \& Matallanas 2001). Studies that included B. grallator (Goode \& Bean, 1886) noted that they consume larger gelatinous prey that exist higher in the water column, with $B$. grallator possessing extremely elongated caudal and pelvic elements that allows them to reach heights necessary to feed on this type of prey (e.g. Crabtree et al. 1991; Gartner et al. 1997). While there has been no direct observation of filter-feeding in the genus, it is highly probable that the upwards or forward placement of pectoral fins observed in sitting tripodfishes play a role in the identification of food that provides an alert to ingest prey. Across Bathypterois taxa, the eyes are heavily reduced, suggesting they are of little to no use in locating food sources (e.g. Munk 1965; Sulak 1977a).

This paper describes the locomotion of a tripodfish from the genus Bathypterois, including the first detailed observation of how each fin is being utilized for 'landing' on the sea floor. The only previous account of tripodfish locomotion and landing was given by Sulak (1977b), where he observed several tripodfish specimens from the DSRV Alvin and noted that when startled, the individuals would swim horizontally and then vertically for a short distance before slowly descending to the sea floor, landing on their outstretched pelvic and caudal elements. The video observation described here was collected off the continental slope in the Atlantic Ocean within the Campos Basin, Brazil as part of the SERPENT Project (Scientific Environmental ROV Partnership using Existing Industrial Technology). The SERPENT project is a collaboration between industry and academia that gives scientists access to industry-owned remotely operated vehicles (ROVs) when not in industrial use. This provides for a constant network of marine life surveillance that would otherwise be difficult to maintain (Benfield 2007).

\section{Materials and methods}

On 6 February 2010 a Triton XL32 ROV operated by Technip recorded $31 \mathrm{~s}$ of a tripodfish at a depth of $1443 \mathrm{~m}$ in the Campos Basin, Brazil (21 deg 13' 01" S, 39 deg $58^{\prime} 23^{\prime \prime}$ W) near a deep constructor rig. The crew of the ROV observed the specimen initially swimming slowly away from the ROV, which was followed by the specimen turning around and 'landing' on the sea floor. A high quality video of this observation was obtained from Jones et al. (2010) upon request. The video itself is available for viewing at http://archive.serpentproject.com/ $1772 /$.

\section{Results}

Six species of Bathypterois are known from the Atlantic Ocean of Brazil (Franco et al. 2009), and the taxon in this observation has been identified here as Bathypterois grallator (Goode \& Bean, 1886). The specimen in the video was identified as $B$. grallator because it lacks an adipose fin (Franco et al. 2009), has extremely pronounced caudal and pelvic fin elements that are longer than the SL of the body, and has relatively short pectoral fins that are held at a slightly backwards inclination (Kenneth J. Sulak, personal communication). This specimen was observed at a depth of $1443 \mathrm{~m}$, which falls within the depth range of $B$. grallator specimens previously collected in Brazil (1000-2100 m, Franco et al. 2009). Unfortunately, the video is of insufficient quality to make any counts of fin elements or gather other meristic data. Laser scaling information was not available, and there are no references for size in the video, so the total length of the specimen itself is undetermined. Adult specimens of $B$. grallator recovered in Brazil by Franco et al. (2009) had a total length range of $136-330 \mathrm{~mm}$. 

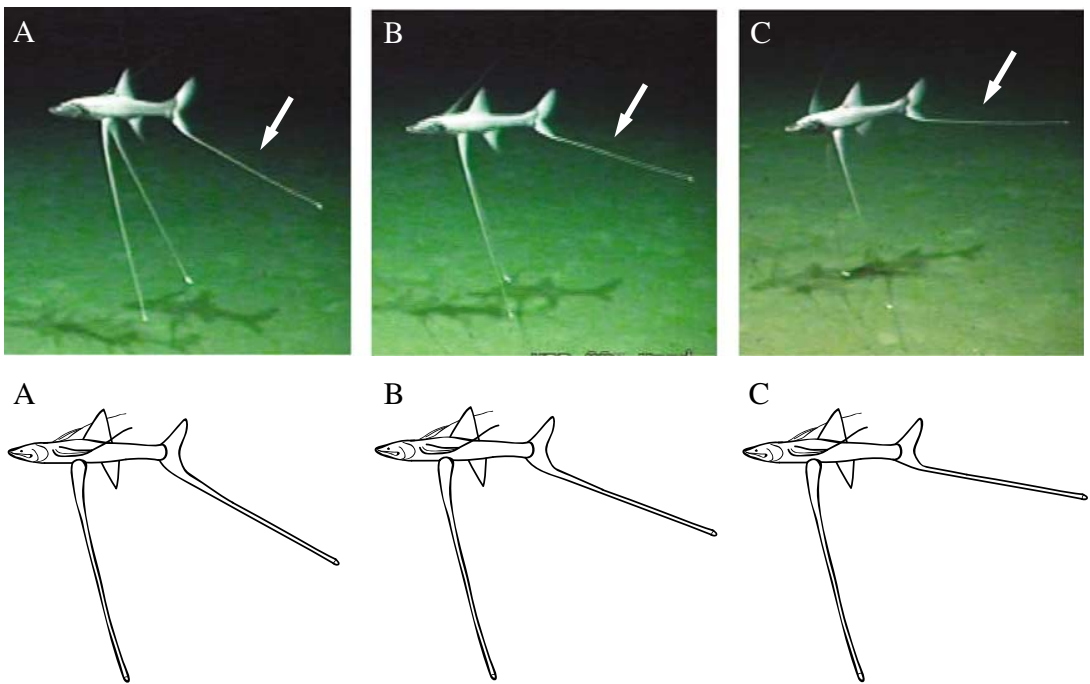

Figure 2. Swimming movements of Bathypterois grallator (Goode \& Bean, 1886) from a depth of $1443 \mathrm{~m}$. See results for description of movement.

As the specimen swims away from the ROV, the body and caudal fin are observed providing the propulsive force for locomotion as the body undulates in a wave moving anteriorly to posteriorly, with movement limited in the anterior portion of the body as seen in Figure 2. The dorsal and anal fins are fully erect with no undulation or oscillation. The pectoral fins are outstretched horizontally and laterally from the body, with the elongated elements trailing behind. The pectoral fins do not appear to undulate or oscillate, and are not contributing to propulsion. The pelvic fins are erect in a downwards position with the elongated elements remaining perpendicular to the body of the fish and held above the substrate of the sea floor. The elongated caudal fin element is also perpendicular to the body of the fish at an angle, moving and swaying pendulum-like with the undulating movement of the caudal fin.

After swimming for $13 \mathrm{~s}$ the specimen begins to slow down and turns slightly to face the ROV. As the fish slows, the undulations of the body decrease in magnitude and become less pronounced anteriorly. The caudal and anal fins remain fully erect, as do the elongated elements in the pelvic fins. Once the specimen stops forward movement, it begins to slowly descend towards the substrate of the sea floor, keeping its body rigid with slight undulations in the caudal region that maintains positioning. The lack of scale makes it difficult to ascertain exactly how far from the substrate the specimen is when it begins its descent, but in Sulak's (1977b) account he observed tripodfish individuals descending only a few metres, which is a reasonable approximation in this observation as well. During this descent, the elongated elements of the pelvic fins maintain their perpendicular placement to the body of the fish, while the elongated elements of the caudal fin begin to move from a perpendicular to parallel position with the body as seen in Figure 3.

While descending, the pectoral fins remain in a wing-like position extended laterally and horizontally from the body. Once the elongated pelvic-fin elements contact the substrate with their pads, which are visible as small white bulbs in the video, the specimen begins to move the elongated caudal-fin element from a stiffened parallel to perpendicular position that contacts the substrate as seen in Figure 4. This completes the formation of the tripod stance. Once the fish first contacts the substrate with its pelvic fins, the pectoral fins begin to slowly move from their horizontal position to the upwards position which continues after the caudal element has contacted the substrate (Figure 4). The video ends as the ROV begins to move in closer to the now stationary specimen, causing a cloud of muddy substrate to engulf the fish.

\section{Discussion}

This video observation provides the first documentation of a tripodfish swimming with periodicity and not in an alarmed state. We interpret the locomotive pattern (periodic swimming followed by landing) as it is described here as "bathypteroiform" (Figure 5E), which is unique to taxa within Bathypterois. The benthonic specimen of Bathypterois grallator observed exhibits periodic swimming, which is classified by Sfakiotakis et al. (1999) as repetitive cyclical movements that propel the fish over large distances at a constant speed. The specimen demonstrates body and/or caudal fin (BCF) locomotion, specifically periodic propulsion (Webb 1984), where thrust is 

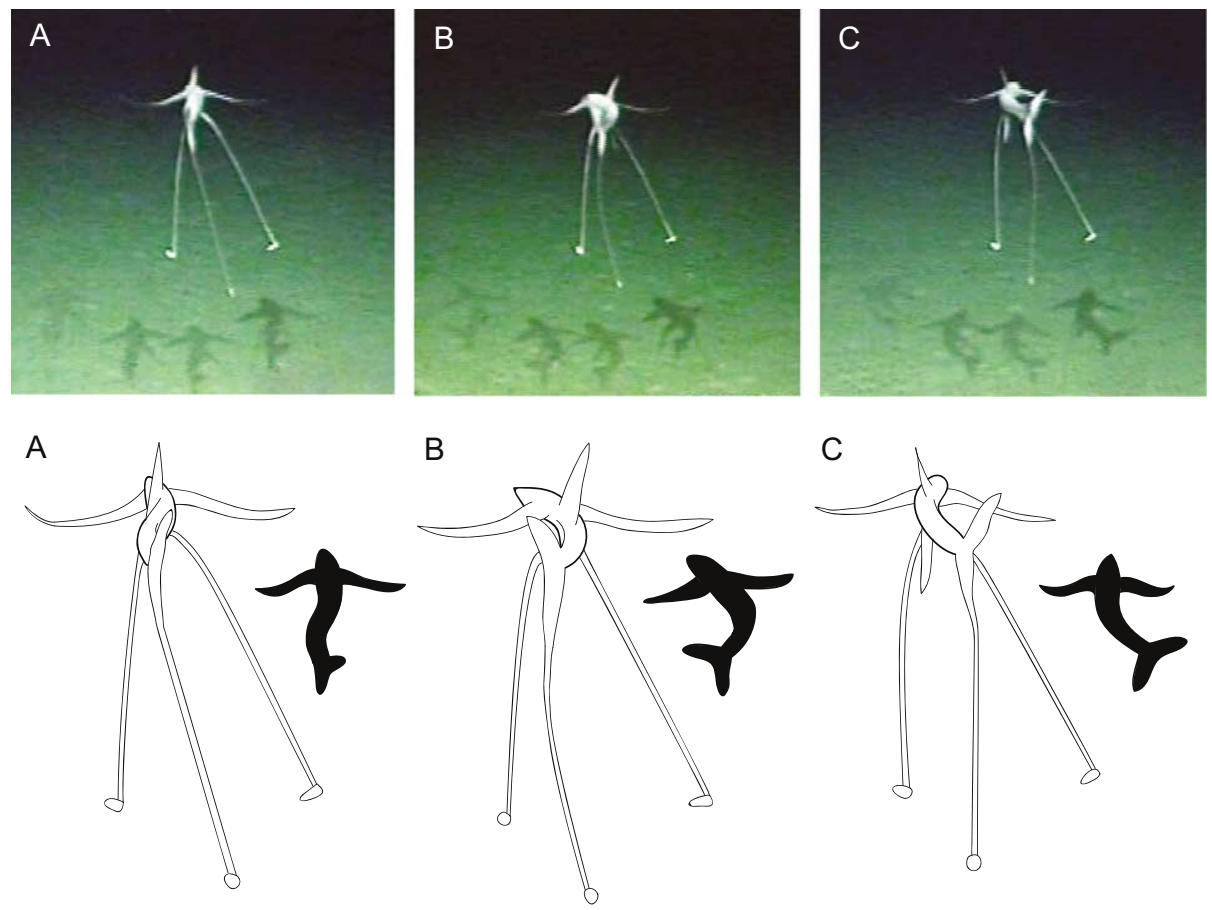

Figure 3. Rising of elongated caudal fin element prior to landing in Bathypterois grallator (Goode \& Bean, 1886).

generated by bending the body through the caudal fin in a backward-moving wave that propels the fish forward (Figure 2) (Breder 1926; Webb 1984;
Sfakiotakis et al. 1999). The fish is observed to be a subcarangiform BCF swimmer, where the propulsive wave appears to be present in large undulations along
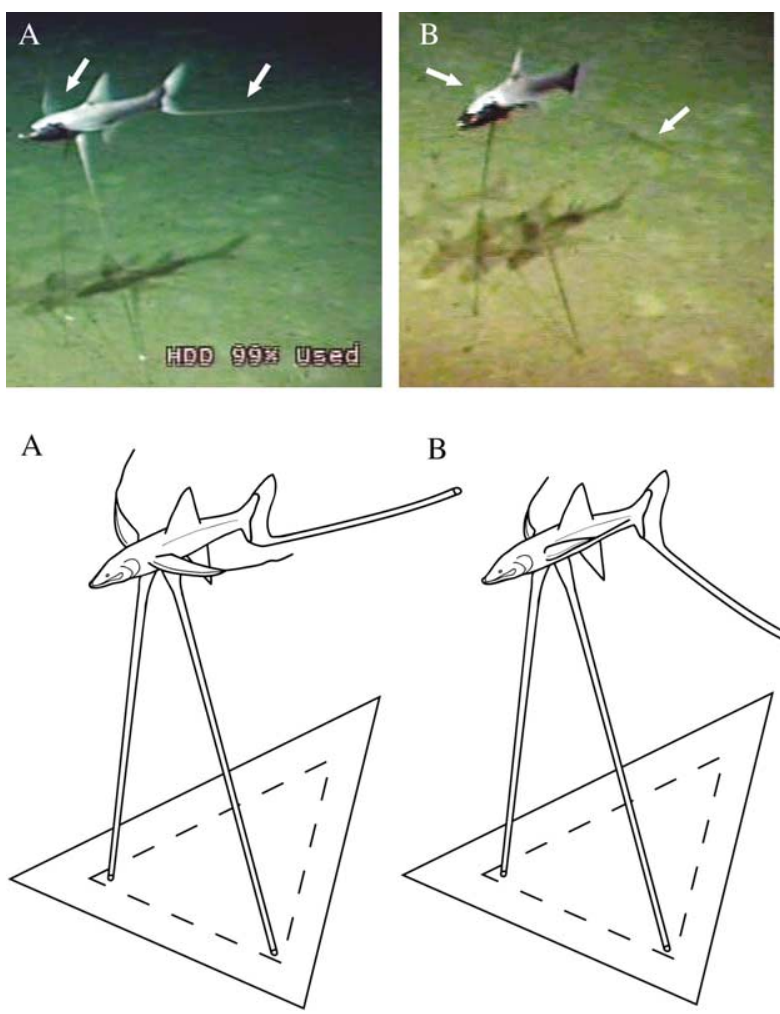

B

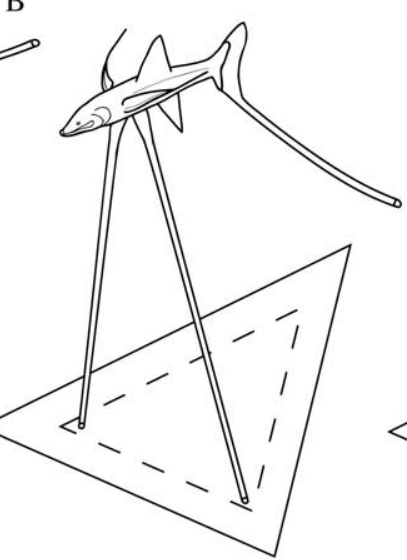

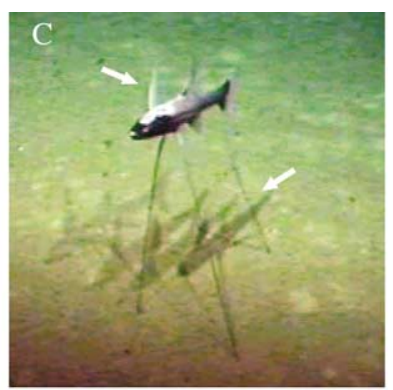

C

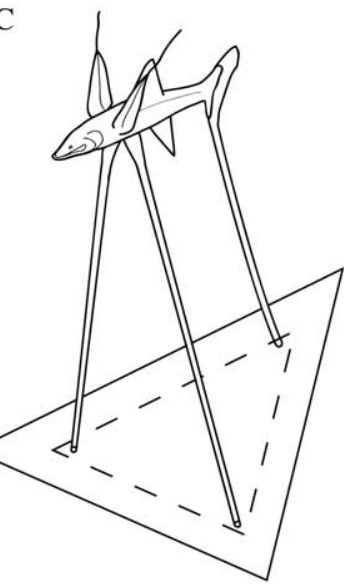

Figure 4. The elongated caudal fin element is lowered from a parallel to perpendicular position until it contacts the deep-sea substrate following the contact of the elongated pelvic fin elements. The pectoral fins are moved from a horizontal wing-like position to an upright position once contact with the substrate has occurred. 

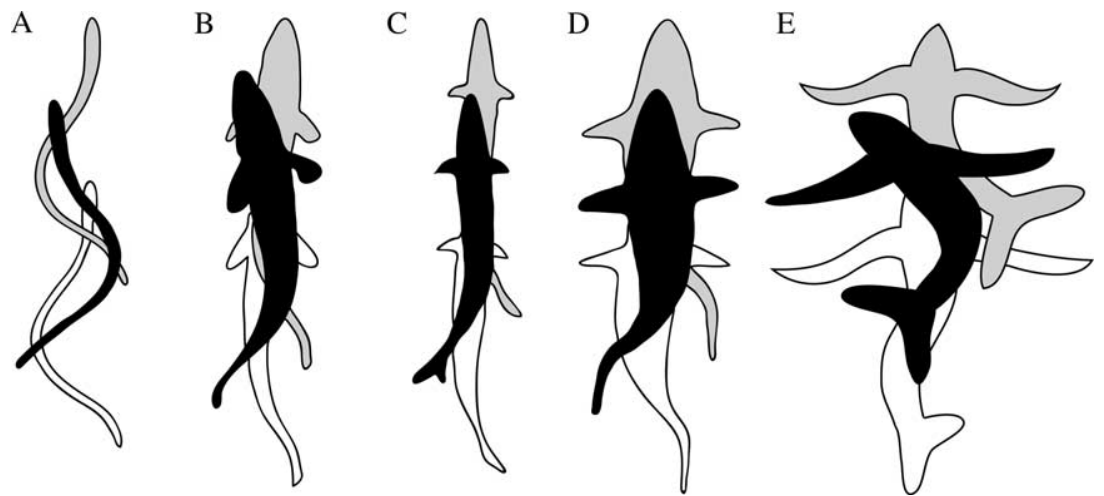

Figure 5. Body and/or caudal fin locomotion including (A) anguilligorm, (B) subcarangiform, (C) carangiform, (D), thunniform, and (E) "bathypteroiform" in Bathypterois grallator (Goode \& Bean, 1886). Illustrations A to D are redrawn and modified from Lindsey (1978).

the majority of the body, although restricted anteriorly (e.g. Breder 1926; Lindsey 1978) as seen in Figure 5. Subcarangiform swimmers tend to have less rigid bodies and caudal fins, allowing for greater mobility and turning with little to no recoil. Subcarangiform movement is not as fast or efficient a swimming mechanism as carangiform or thunniform modes, but it provides the tripodfish with the mobility necessary for effectively turning, hovering, and landing in its benthic deep-sea habitat.

During bathypteroiform movement, the specimen maintains erect dorsal and anal fins that do not undulate, suggesting these fins are being used solely for stabilization in tripodfishes and have no impact on propulsion as seen in Figures 2-4. The pectoral fins are not used at all for propulsive locomotion, as the extended fins are held laterally and horizontally from the body as a wing like structure with no oscillatory or undulating movements (Figure 2). This implies that the functional role of tripodfishes pectoral fins during bathypteroiform movement is to assist with stability, including while swimming, turning, hovering, and landing (Figures 2-4). Additionally, the elongated elements of the pectoral fin never contact the substrate during or after movement, with the pectoral fins beginning to move into an upwards position shortly following initial contact with the substrate of the pelvic fins (Figure 4). Once stationary, the functional role of the pectoral fin changes, with the specimen positioning the fins into the commonly observed upwards position that is hypothesized to play a sensory role in the identification of potential food sources (Figure 4) (Sulak 1977a).

Of particular interest is how the elongated elements of the pelvic and caudal fins are utilized in bathypteroiform movement. The elongated elements of the pelvic and caudal fins are perpendicular to the body and held above the substrate of the sea floor while swimming as seen in Figure 2. As the tripodfish descends, the elongated element of the caudal fin is elevated to a position parallel with the body (Figure 3), most likely to keep it from contacting any substrate prematurely. This independent movement of the elongated caudal fin element has never been observed previously, suggesting that there may be some muscular and/or nerve specialization in the caudal fin of tripodfishes that requires further investigation.

The pads of the elongated pelvic fin elements are first to contact the substrate during landing. Once the pelvic fins contact the substrate, the caudal fin element is independently brought down from its parallel position to the sea floor (Figure 4). The ability to independently move the elongated caudalfin element confers a functional ability that would allow for flexibility in changing the vertical angle of its body relative to the substrate. Potential reasons for this adaptation include allowing the fish to keep the same kind of position relative to its environment given different substrate topography, or alter its body angle given a change in the position of its benthopelagic food source.

Sulak (1977b) described tripodfish locomotion (bathypteroiform movement) as awkward and inefficient due in part to their highly specialized fin elongations. Tripodfishes are not locomotor specialists as defined by Webb (1984), as they lack locomotive specializations that are often constrained to exploit foraging behaviour. For example, locomotive specialists may hunt widely dispersed food by traveling great distance while expending the least amount of energy (e.g. Thunnus), or having transient propulsive specializations that allow ambush predators to take evasive prey through rapid acceleration (e.g. Esox) (Webb 1984). Locomotor generalists are more common among actinopterygians than specialists (Webb 1982a), which may be attributed to the fact that generalists tend to feed on food sources that are smaller in size (Webb 1984). Because tripodfishes are likely filtering benthopelagic plankton (e.g. Crabtree et al. 1991; Carrassón \& Matallanas 2001), the swimming patterns of filter feeders are of 
particular importance. Webb (1984) suggested that generalist locomotion is evolutionarily adequate when food items are small and of good density such that filter-feeding is an option, but that there is also a tradeoff for filter-feeders where net energy gains would be diminished by the locomotive specializations that would be required to increase prey intake (Webb 1982b). As a result, locomotive specializations are often diminished in filter feeders in favour of non-locomotor adaptations that are associated with feeding (Webb 1984).

As discussed earlier, tripodfishes exhibit a wide range of non-locomotor adaptations that are associated with their feeding behaviour within their deep-sea habitat. These specializations include the elongated caudal and pelvic fin elements that assist with reaching the specific water column regions where they are likely filter-feeding benthopelagic plankton, and the modified pectoral-fin structures that are likely being used to locate these prey sources. These highly modified pectoral-fin structures do not appear to have a propulsive locomotive role in bathypteroiform movement; rather they appear to provide stabilization either during or immediately following landing (Figures 2-4), such as the wing-like position of the pectoral fins as the fish descends to the substrate in the video observation. The elongated elements are potentially hindering locomotive efficiency in tripodfishes as the fish swims in favour of adaptations that assist with food collection in their deep-sea environment once bathypteroiform movement is complete and the fish is resting on the substrate of the sea floor.

While this observation sheds new light on how tripodfishes navigate their deep-sea environment and utilize their elongated elements for landing, there is still much to learn about the biology of these enigmatic fishes. Direct video observations of tripodfishes are rare, and fundamental issues regarding their behaviour and ecology are still unknown. While much can be inferred from studying the morphology of these fishes, it is still unclear exactly how tripodfishes eat, although ecological and morphological studies suggest filter feeding (e.g. Sulak 1977a; Crabtree et al. 1991; Gartner et al. 1997). Likewise, the reproductive behaviours of these simultaneous hermaphroditic fishes are wholly unknown, although Sulak (1977a) suggested they may be seasonal spawners. While sustaining and maintaining deepsea video surveillance is a difficult and expensive endeavor, collaborative projects such as SERPENT are providing an opportunity to gain new insights into the biology of deep-sea fauna.

\section{Acknowledgements}

We would like to thank the NOAA-supported SERPENT Project for providing access to this video observation and A. Gates for supplying us with a high resolution version for analysis. Additionally we thank K.J. Sulak for his comments and suggestions regarding the manuscript. Support for this study was provided by the Chakrabarty lab at Louisiana State University's Museum of Natural Science, National Science Foundation Doctoral Dissertation Improvement Grant (DEB 0910081), NSF Euteleost Tree of Life (DEB 0732819) and NSF DEB 0916695.

\section{References}

Baldwin CC, Johnson GD. 1996. Aulopiform interrelationships. In: Stiassny MLJ, Parenti LR, Johnson GD, editors. Interrelationships of Fishes. San Diego, CA: Academic Press, p 355404.

Bauchot ML. 1962. Description d'un nouveau Bathypterois méditerraneen (Poisson Clupéiforme Bathypteroidae). Affinités et remarques sur plusiers especès du genre. Note préliminaire. Bulletin du Museum D'Histoire Naturelle Paris sér. 2 34:26566.

Benfield MC. 2007. SERPENT: Industry and academia team-up to explore marine life in the Gulf of Mexico deepwater region. Marine Technology Reporter 50:28-37.

Breder CM. 1926. The locomotion of fishes. Zoologica 4:159256.

Carrassón M, Matallana J. 2001. Feeding ecology of the Mediterranean spiderfish, Bathypterois mediterraneus (Pisces: Chlorophthalmidae), on the western Mediterranean slope. Fishery Bulletin 99:266-74.

Crabtree RE, Carter HJ, Musick JA. 1991. The comparative feeding ecology of temperate and tropical deep-sea fishes from the western North Atlantic. Deep-Sea Research 38:1277-98.

Davis MP. 2010. Evolutionary relationships of the Aulopiformes (Euteleostei: Cyclosquamata): A molecular and total evidence approach. In: Nelson JS, Schultze HP, Wilson MVH, editors. Origin and Phylogenetic Interrelationships of Teleosts. München: Verlag Dr. F. Pfeil, p 431-70.

Franco MAL, Braga AC, Nunan GWA, Costa PAS. 2009. Fishes of the family Ipnopidae (Teleostei: Aulopiformes) collected on the Brazilian continental slope between $11^{\circ}$ and $23^{\circ} \mathrm{S}$. Journal of Fish Biology 75:797-815.

Gartner JV, Crabtree RE, Sulak KJ. 1997. Feeding at depth. Chapter 4, In: Randall DJ, Farrell AP, editors. Physiology of Deep-Sea Fishes, Vol. 16. San Diego, California: Academic Press, p 115-93.

Goode GB, Bean TH. 1886. Reports on the result of dredging... XXXVIII. Description of 13 species and 2 genera of fishes from the Blake collection. Bulletin Museum Comparative Zoology Harvard 12(5):153-70.

Jones DOB, Gates AR, Curry RA, Thomson M, Pile A, Benfield M. 2010. SERPENT project. Media database archive. Available online at http://archive.serpentproject.com/1772/ (accessed 11 November 2010).

Lindsey CC. 1978. Form, function and locomotory habits in fish. In: Hoar WS, Randall DJ, editors. Fish Physiology Vol. VII Locomotion. New York, NY: Academic, p 1-100. 
Mead GW. 1958. Three new species of archibenthic iniomous fishes from the western North Atlantic. Journal of the Washington Academy of Sciences 48(11):362-72.

Munk O. 1965. Ocular degeneration in deep-sea fishes. Galathea 8:21-31.

Nelson JS. 2006. Fishes of the World, 4th ed. New York, NY: John Wiley \& Sons. 624 pages.

Sfakiotakis MD, Lane M, Davies JBC. 1999. Review of fish swimming modes for aquatic locomotion. IEEE Journal of Oceanic Engineering 24:237-52.

Sulak KJ. 1977a. The systematics and biology of Bathypterois (Pisces: Chlorophthalmidae) with a revised classification of benthic myctophiform fishes. Galathea 14:49-108.
Sulak KJ. 1977b. Alvin, window in the deep. Sea Frontiers 23:113-19.

Webb PW. 1982a. Locomotor patterns in the evolution of actinopterygian fishes. American Zoologist 22:329-42.

Webb PW. 1982b. Fast-start resistance of trout. Journal of Experimental Biology 96:93-106.

Webb PW. 1984. Body form, locomotion and foraging in aquatic vertebrates. American Zoologist 24:107-20.

Editorial responsibility: Franz Uiblein 